\title{
Factors Influencing the Trilingual Education in Leshan Ebian Yi Autonomous County
}

\author{
Huang Jian ${ }^{1}$ \\ ${ }^{1}$ School of Foreign Languages, Leshan Normal University, China \\ Correspondence: Huang Jian, School of Foreign Languages, Leshan Normal University, Leshan, Sichuan, China. \\ Tel: 86-138-9066-3663. E-mail: shaominmatt@sina.com
}

This research is financed by the Research Projects of Leshan Normal University (No.S1146) and Sichuan Foreign Language Literature Research Center (No.SCWYH12-12)

Received: March 15, 2013 Accepted: April 10, 2013 Online Published: May 8, 2013

doi:10.5539/elt.v6n6p148 URL: http://dx.doi.org/10.5539/elt.v6n6p148

\begin{abstract}
Language is symbolic of nationality culture (Claire, 2000). Trilingual education to the minority students is necessity for inheriting and developing their national culture. This survey studies the trilingual education in practice, analyses the existing trilingual education problems in Sichuan Leshan minority areas and indicates the prospect of the future studies, so as to offer valuable references for the trilingual education practice and language policy making.
\end{abstract}

Keywords: trilingual education, questionnaire survey, Yi nationality, multi-cultural education

\section{An Introduction of Ebian Yi Autonomous County}

\subsection{The Basic Situation in Ebian Yi Autonomous County}

Leshan Ebian Yi Autonomous County in Sichuan, China, with population of 46 thousand, is one of the branches in Yi nationality. There are 9745 Yi students in Ebian, including 5360 primary school students and 4415 high school students. The total number of existing school staff is 1526 and 1320 are full-time teachers. 322 of them are Yi nationality.

\subsection{The Local Trilingual Education Policy in Ebian}

When it comes to the local policy-making, the local government realized the importance of trilingual education and put forward some specific teaching project. All schools offer Yi language course for the Yi students and all the students should attend to English course. But there is only 1 Yi language course for the students each week. The Yi language teachers try to focus on fostering students interests of the Yi culture. The teaching materials are from Erbi which is some traditional Yi culture introduction book.

\section{Research Tool}

\subsection{Hypothesis of the Investigation}

From some researcher, when learning some foreign language, bilinguals are more pragmatic functional and productive than monolinguals (Jorda M. P. S, 2005). According to the daily English teaching experiences in Leshan Normal University, we find out that the Yi students, bilinguals speaking Yi language and Standard Chinese, have great difficulties in English learning, especially in pronunciation and enlarging vocabulary. We believe that many special features and problems in the present trilingual classroom must be existed to the trilingual teachers from the Chinese minority areas when they carry out their presentation of the lessons without any theory or technology support.

\subsection{A Questionnaire Survey}

In order to inquire into the problems, a general investigation is conducted on a minority high school in Mabian Yi nationality autonomous county. The author believes that only after a careful analysis of the collected data, he could possibly develop effective teaching strategies in the trilingual education in the Chinese ethnic nationality areas. The analysis of problems that are found through the author's presentation would be constructed by the data 
collected from questionnaire survey, interviews and classroom observations.

\subsubsection{Design of the Questionnaire}

The design of the questionnaire is borrowed from some other researchers including Li Xiaohong and Liu Quanguo (Li Xiaohong, 2010; Liu Quanguo, 2007).

The questionnaire contains fifteen multiple choice questions and three interview questions. All the questions are allowed to give more than one answer or other explanations.

The method of data collection and the questionnaires are designed to be as non-threatening as possible. Many questions are to be asked in a conversational manner, leaving openings to a variety of responses and suggestions.

The questionnaire consists of two sections. The first section includes the participants' personal information while the items of the second section address learner's understanding to their own needs and goals in trilingual education.

\subsubsection{Procedures of Research}

There are three main steps of this questionnaire survey: pilot testing, delivering and data collecting, and data sorting and analyzing.

First of all, the questionnaire was administered to my colleagues and some students. The participants in the pilot-testing were asked to look through all the questions on the questionnaire and to make comments about both the statements and the construction of the questionnaire in order to receive the feedback dealt with whether the questions were clearly stated and whether they were receptive. Moreover, in order to make sure that every survey responder would interpret the survey items intended, the author asked responders to tell what they got from survey items. Thus, on the basis of the feedback, necessary changes and revisions were made. Some questions which were misleading, misunderstanding, ambiguous or unclear were deleted. In addition, some items were reformulated and some items were added to cover issues which arose in the discussions with the researcher's colleagues.

The purpose of the survey was explained to the students before administering the questionnaires. We also claimed to the participants that there were no risks when participating in this survey.

In order to make sure that all the questions could be understood clearly to the students, we print the questionnaires in Chinese. All the questionnaires were returned to the teachers immediately after the students finished it in class.

\section{Problems Discovered by Means of a Questionnaire Survey}

A questionnaire survey with the students is used to find out the primary data of problems about their trilingual education and their needs in trilingual education. I will illustrate the procedures of the questionnaire survey and the problems out of the results of the survey.

\subsection{The Basic Data Collection}

Altogether there are 180 students in a minority Middle school from Ebian who participate in the questionnaire survey. The students are randomly selected

After thorough examination, 7 copies are invalid because of the incompleteness or illegibility of the answers to the questions, and the rest 173 copies are carefully filled which make the valid rate of data $96 \%$. Among the 173 participants, 83 are female students which occupy $49 \%$ of all and 90 are male students which occupy $51 \%$.

\subsection{Problems Discovered by Means of the Questionnaire}

In the questionnaire survey, the original data is obtained directly through answers to questionnaires. The author could be benefited a lot to design and improve the new thoughts and suggestions on trilingual teaching approaches and methods through the analyzing of raw data and the sorting of responders' open answers. And all the questions are supposed to investigate two aspects, including the current language use situation and the attitude of the Yi students towards trilingual education, as following:

\subsubsection{The Situation of the Language Use among the Yi Students}

Table 1. Question 1, what's your mother language?

(Data source from the questionnaire)

\begin{tabular}{lll}
\hline Questionnaire Items & Frequency & Percent \\
\hline Yi language & 132 & $76 \%$ \\
\hline Chinese & 41 & $24 \%$ \\
\hline Yi language and Chinese & 0 & $0 \%$ \\
\hline
\end{tabular}


Table 2. Question 6: what language do you use when you communicate with your family?

(Data source from the questionnaire)

\begin{tabular}{lll}
\hline Questionnaire Items & Frequency & Percent \\
\hline Yi language & 156 & $90 \%$ \\
\hline Chinese & 0 & $0 \%$ \\
\hline Yi language and Chinese & 17 & $10 \%$ \\
\hline
\end{tabular}

There appear contradictions between the data from these two questions. 41 students' mother tongue is Chinese but only 17 of them speak Chinese home. According to the interview to the local people, we find out that these students' parents are bilingual speakers and they don't think Yi language is useful to their children's further studies so they give their children Chinese as their mother tongue. Nevertheless, these parents are busy in working so their children are properly brought up by their grandparents who could only speak Yi language.

Table 3. Question 7: what language do you use in school?

\begin{tabular}{lll}
\hline Questionnaire Items & Frequency & Percent \\
\hline Yi language & 96 & $55 \%$ \\
\hline Chinese & 0 & $0 \%$ \\
\hline Yi language and Chinese & 77 & $45 \%$ \\
\hline
\end{tabular}

(Data source from the questionnaire)

Question 12: what language would you prefer in reading?

Question 13: what language would you prefer in watching TV?

All the Yi students prefer in reading and watching TV in Chinese.

Interview question: what is the biggest barricade in the trilingual education that you receive?

Many students talked that writing and reading are the most difficult parts in English and Yi language learning while most of them could do listening, speaking, writing and reading well in Chinese.

According the analysis to these questions, we could draw some conclusion as following:

1. Most of the Yi students prefer to use Chinese in school while Yi language is used in family. According to the author's observation in the local schools, there is only 1 Yi language course each week prepared for the Yi students.

2. English could be only used by a small margin. Chinese is the medium language of introduction in daily teaching. Yi language sometimes could be used in communicating with their friends and families.

3. We schools don't have enough Yi language teaching materials to attract students.

\subsubsection{The Attitude of Trilingual Education among the Yi Students}

Table 4. Question 8: what's your feeling when you speak Yi language to others, while the response is in Chinese?

\begin{tabular}{lll}
\hline Questionnaire Items & Frequency & Percent \\
\hline Unpleasant & 149 & $86 \%$ \\
\hline Indifference & 24 & $14 \%$ \\
\hline
\end{tabular}

(Data source from the questionnaire)

Question 2: why you keep using and learning Yi language?

From this question, we could easily find out that Yi students have deep feeling towards Yi language and Yi nationality. 
Table 5. Question 3: what is the most important Yi national characteristic?

\begin{tabular}{lll}
\hline Questionnaire Items (Question Number) & Frequency & Percent \\
\hline Yi language & 57 & $33 \%$ \\
\hline Dress & 96 & $55 \%$ \\
\hline Habitude & 168 & $97 \%$ \\
\hline Music & 6 & $3 \%$ \\
\hline
\end{tabular}

(Data source from the questionnaire)

All the participants answered in multiple choices although logically, this question should be answered with one answer. The statistics show that most of them feel "Habitude" and "Dress" could reflect their culture. Unpleasantly, only one third think Yi language is important to their culture.

Question 5: what you think if the Yi language course is canceled?

More than $80 \%$ participants make their attitudes that they feel indifferent if the Yi language course is canceled or not. But they do have deep feeling in Yi culture and language from the conclusion of question 4 and question 2. So we suppose if there appear some problems in the Yi language teaching methods and if the teaching materials are suitable.

Table 6. Question 4: why do you keep using and learning Chinese?

\begin{tabular}{lll}
\hline Questionnaire Items (Question Number) & Frequency & Percent \\
\hline Convenient & 57 & $33 \%$ \\
\hline Official Language & 90 & $52 \%$ \\
\hline My Favorite Language & 10 & $6 \%$ \\
\hline Other Reason & 16 & $9 \%$ \\
\hline
\end{tabular}

(Data source from the questionnaire)

Generally, the Yi students feel it convenient to use Chinese as it is the official language.

Question 10: Which languages do you like, Yi language, Chinese or English?

Do you like Yi language? Do you like Chinese?

More than $85 \%$ of the students expressed their interests in learning these to languages, but when we come to the question: Do you like English? Only 51\% of the participants said they liked learning English; 33\% of them expressed their indifferent attitude towards English learning and 16\% indicated that they dislike English learning.

Interview question: Do you enjoy the teaching methods that your teachers use in trilingual education?

Most of the students indicate that they enjoy the teaching methods they are received. But in fact, according to the author's observation in the English classroom, the students didn't perform their interests in this course.

Interview question: What do you think about trilingual education?

This question is inadequate to the Yi students because they have no idea of what trilingual education is.

According the analysis to these questions, we could draw some conclusion as following:

1. Nearly all the students prefer Chinese while many of them feel exhausted in English learning. And they all neglect the Yi language learning because they think that Yi language is not widely used in their daily life and it is not helpful to the College Entrance Examination.

2. The Yi students could not be attracted by the trilingual education Textbooks and teaching methods.

3. Most of the Yi students think the Yi traditional habitude could reflect the Yi culture. Only a few students realize the importance of Yi language.

4. There appears a complicated attitude among the Yi students towards trilingual education. In one aspect, they want to integrate into Han culture so they speak Chinese in schools, on another aspect; they keep speaking Yi language home and feel proud of their national habitude. We also cast doubt on the attitude of the Yi students to English learning because from the interviews to the students, without precious consultation, they agree that 
English is widely used as some international language but they don't need to learn it well. The indifferent attitude to English learning influences the English teaching greatly.

Hence, for sentimental reason, they speak Yi language and for rational reason, they speak Chinese. But it is a key issue how to promote the minority students' motivation of English learning.

\section{Problems Discovered by Means of English Classroom Observations}

There are some detailed problems revealed from the observation in classroom. Classroom observation is an integral part of our study. Our observation focused on the teachers' performance as well as the students' responses. There are more than 70 students in one class. It is impossible for English teachers to give consideration to all students especially in English listening and speaking training. The class is teacher-centered. Students are not active in classroom and they give no responses to teacher's questions.

Moreover, I am still highly questionable to the teachers' pronunciation and intonation. I believe that the local teachers' pronunciations are commonly influenced by their dialect.

According to the investigation, we find out that:

1. The students strongly believe that trilingual education is of great use. They have to learn Chinese well because it is widely used in their daily lives while English is a necessary language tool if they want to continue their further studies.

2. Yi language is not widely used. But Yi language education should be the important means to inherit and popularize the Yi culture.

3. There is a poor quality of trilingual education. The schools can not afford enough education resources to the students. We do not have a complete trilingual education system. The teaching materials that the Yi students use are the same as the Han students. The textbooks don't contain Yi background information.

\section{The Countermeasures to the Previous Trilingual Education Methodologies}

\subsection{The Principle of Trilingual Education Aim Setting}

The teaching aim of trilingual education must satisfy the students' thirsts for knowledge. There appear complicated needs of the minority students for knowledge because of the student differences of age and social background. The ideological systems of the students have been greatly constructed from their family education and community environment. Trilingual teachers should concentrate on the disparities among the students, which is the basic principle of trilingual education aim setting. In another word, we must pay close attention to the minority learners' status of development.

Moreover, the setting of trilingual education aim should be considerate of the demands from the modern social life. Generally speaking, there are distinctive economic and cultural features in minority areas. People living there also have their distinctive living requirement. Thus, the students' thirsts for knowledge are changeable, mingling with the social development.

In a word, the principle of the trilingual education aim consists of the minority students' thirsts for knowledge as well as the social needs.

\subsection{Establishing Multi-Culture Education Concept}

The process of language learning could be influenced a lot by learners' psychological changes, while the psychological changes are conditioned by the learner's culture background. The author believes that the multi-culture understanding of the students has an intervening effect between learning motivation and learning satisfaction. Hence, the combination of multi-culture and trilingual education could obviously arouse the effects of trilingual learning.

It has been nearly 90 years since the terminology of multi-cultural came into being. The western multi-culture education has been greatly succeeded, which enlightens the trilingual education in minority areas. From the prospective of the cultural diversity, trilingual teachers, especially the English teachers, should establish the concept of multi-cultural education and implement multi-cultural subjects in ethnic schools. The courses must contain ethnical, Chinese and western cultural background information. The purpose of setting multi-cultural education in Yi trilingual education system is of promoting Yi students' ability of communication to other nationalities and understanding to other cultures, which could improve the harmonious relationship among nationalities and social equity. What's more, multi-cultural education also enables ethnic students to expand new horizons and a wider range of knowledge. And it is the only way for them to inherit and carry the minority culture forward. 
The concept of multi-cultural education must be integrated into all aspects of trilingual education, including the teaching methodology, course setting, text book compilation and policy making.

\section{The Further Studies on Trilingual Education}

In order to solve these problems, I strongly recommend other researchers probe into the following aspects.

Firstly, we need to improve the efficiency of trilingual education. 1). Establish a theoretical system of trilingual education: Specific courses should be offered for Specific ethnic nationalities, including curriculum standard, teaching materials and teaching aims. 2). Develop different teaching models for different ethnic nationality areas. The theoretical research of trilingual education should be based on empirical studies and the theories from linguistics. Only in this way, we could educate the ethnic national students according to their nature abilities.

Next, the running system of trilingual education in ethnic nationality areas could not solve the difficulties of the trilingual education. We should probe into trilingual policy making research. Scientific policy and law system should be established as the guarantee for trilingual education, which could insure the promotion of trilingual teacher education and the practice of new trilingual teaching models.

Then, we should promote and perfect the trilingual teacher education system. The ethnic nationality areas are not attracted to highly educated and high-quality teachers. We could only train the local trilingual teachers. How to reform the trilingual teacher education models should be focused.

Finally, I am wondering if we could extend the objects of trilingual studies (Huang Jian, Wang Hui, 2010).The objects of research could not only exist in primary and high school students, but also the students in high education and vocational education; not only the ethnic national students, but also the Han students. If it is possible we give ethnic nationality culture lessons to the Han students?

\section{References}

Claire Kramsch. (2000). Language and Culture. Shanghai: Shanghai Foreign Language Education Press.

Huang Jian, \& Wang Hui. (2012). The Summary and Prospects of the Trilingual Education in China. Guizhou Ethnic Studies, 147(5), 191.

Li Xiaohong. (2010). Tibetan Areas in Gansu Province Investigation of the Trilingual Teaching: Take a National School of Tianzhu Tibetan Autonomous County for Example. College of Education, Northwest Normal University.

Liu Quanguo. (2007). Towards EFL Teachers' Code-Switching in Trilingual Classroom. Southwest University.

Jorda M. P. S. (2005). Third Language Learners: Pragmatic Production and Awareness. Clevedon: Multilingual Matters Ltd. 